\title{
Explicando os efeitos de programas de socialização política: a experiência do Parlamento Jovem no Brasil
}

\begin{tabular}{c}
\hline Mario Fuks \\
Departamento de Ciência Política \\
Universidade Federal de Minas Gerais \\
\hline \hline
\end{tabular}

\begin{abstract}
Resumo: 0 presente artigo investiga, de forma sistemática, as mudanças geradas por programas de educação cívica em seus participantes, oferecendo uma visão integrada dos condicionantes e dos padrões de efeito resultantes. Nossas principais conclusões são: 1) valores são mais resistentes à mudança do que a motivação, o conhecimento político e as atitudes diante de instituições políticas; 2) os ganhos cognitivos e mudanças atitudinais ocorrem com maior intensidade quando o objeto pertence ao universo familiar da experiência; 3) os efeitos sobre a participação política não se manifestam no presente, mas os dados indicam a propensão a maior participação na vida adulta; 4) a qualidade do programa e a motivação do participante condicionam a influência dos demais fatores. O objeto de estudo é o Parlamento Jovem mineiro, em sua edição de 2008. O desenho da nossa pesquisa segue a lógica da pesquisa quase experimental (CAmpbell; Stanley, 1979). A partir de uma amostra não aleatória, foram realizadas, em 2008, duas rodadas de um survey, com 670 entrevistas, sendo 335 antes e 335 após o programa, das quais 167 com participantes e 168 com não participantes.
\end{abstract}

Palavras-chave: socialização política; atitudes políticas; participação política; conhecimento político

\begin{abstract}
This article investigates systematically the changes generated by civic education programs on its participants, offering an integrated view of the determinants and the resulting effect patterns. Our main conclusions are: 1 ) values are more resistant to change than motivation, political knowledge and attitudes towards political institutions; 2) cognitive gains and attitudinal changes are more likely to occur (and with greater intensity) when the object belongs to the universe of experience related to the program; 3) effects on political participation do not occur in the present, but the data indicate a propensity latter in adult life; 4) very often, the quality of the program and the motivation of the participant determine the influence of other factors. The object of study is the Youth Parliament mineiro, in its 2008 edition. Our research design follows the logic of quasi-experimental research (CAMPBELL; STANLEY, 1979). In 2008, a non-random sample of 670 participants completed two rounds of interviews, 335 before and 335 after the program. We interviewed 167 participants and 168 non-participants.
\end{abstract}

Keywords: political socialization; political attitudes; political participation; political knowledge 
Introdução

Um dos grandes desafios com que se defrontam os estudos sobre comportamento político é explicar a mudança, quer seja nas atitudes, na tomada de decisão ou na participação política. Qual é o processo mediante o qual o cidadão apático se torna participativo? O que leva o eleitor a rever a sua decisão sobre o voto? Em que circunstâncias atitudes políticas socialmente enraizadas perdem intensidade e, eventualmente, mudam de direção?

Os estudos clássicos tiveram dificuldade em lidar com processos de mudanças, pois consideraram permanência (LAZARSFeld, Berelson; GAUder, 1965; CAMPBell et al., 1960; ALmOND; VERBA, 1964; PUtNAM, 1996) como o "estado natural" (ECKSTEIN, 1988) do comportamento político. Em nenhuma outra área, a estabilidade das atitudes teve tanto destaque quanto nos estudos sobre socialização política. Mas, contrariando o paradigma clássico, estudos mais recentes mostram, de forma reiterada, que os processos socializadores que ocorrem após a infância e em espaços mais amplos do que aqueles da socialização primária são relevantes para a formação e a transformação do perfil político dos indivíduos, em especial em ambientes com alto fluxo informacional (SEARS; VALENTINO, 1997). Os estudos sobre programas de educação cívica, ancorados nessa nova visão da socialização política, têm identificado mudanças no comportamento político dos participantes (Slomczynski; Shabad, 1998; Finkel; Sabatine, 2000; Galston, 2001; Finkel, 2003; FinKel; ERnSt, 2005; CAMPBELL, 2008; FInKEL; SMITH, 2011; Niemi; JunN, 1998).

O presente artigo compartilha com a literatura sobre educação cívica o objeto de investigação: programas promovidos com a finalidade de formação de cidadãos informados, politicamente ativos e com atitudes e valores congruentes com o regime democrático. No entanto, a grande maioria dos estudos sobre educação cívica não tem como objetivo a análise sistemática dos condicionantes das mudanças ocorridas. A proposta deste artigo é contribuir para superar essa lacuna, oferecendo uma visão integrada dos fatores e dos padrões de efeito resultantes. 0 modelo resultante se apoia em dois estudos (NIEMI; JUNN, 1998; FINKEL; ERNST, 2005) que, em conjunto, consideram fatores de natureza estrutural, referentes ao desenho do programa, e individual, em especial a motivação.

Serão considerados três fatores responsáveis pela criação de condições mais ou menos favoráveis para a mudança no comportamento político a partir do impacto de programas de educação cívica. O primeiro é constituído pelas diferentes dimensões do comportamento político, que inclui atitudes, conhecimento e participação política. Cada uma dessas dimensões tem suas particularidades, em especial no que se refere à permeabilidade à mudança.

O segundo fator são as características do programa, incluindo qualidade, dinâmica, conteúdos e proximidade dos objetos (VALENTINO; SEARS, 1998) em relação ao ambiente da experiência. Espera-se que os efeitos de socialização política dependam de como o programa de educação cívica foi estruturado. Programas participativos e bem executados devem provocar mais mudanças e estas devem ocorrer, com maior destaque, em relação a objetos que fizeram parte do universo da experiência.

Em geral, são esses fatores estruturais que são analisados, deixando pouco espaço para a consideração de fatores individuais. Na nossa proposta, incluímos a motivação individual, expressa 
FUKS, M. Explicando os efeitos de programas de socialização política...

pelo aumento do interesse pelo programa no seu decorrer. Naturalmente, supomos que jovens mais motivados tenham mais a ganhar com o programa.

Além de investigar os fatores que criam condições favoráveis para a mudança no comportamento político, o artigo pretende investigar a ação e a interação entre esses fatores na constituição dos padrões de efeito dos programas. Os efeitos decorrentes se diferenciam não apenas na sua intensidade (fracos, fortes ou nulos), mas também na sua trajetória (diretos, indiretos e tardios).

Ao propor um modelo que explique, de forma integrada, o impacto de programas de educação cívica, pretendemos não apenas contribuir para a elaboração de políticas públicas nessa área, mas, principalmente, para a compreensão dos processos e mecanismos associados a mudança das atitudes, aquisição de conhecimento e incremento do engajamento político. Nesse sentido, o verdadeiro teste do modelo será a sua aplicação em estudos futuros.

Na próxima seção, apresentamos, de forma resumida, os achados da literatura sobre educação cívica a respeito dos fatores que explicam o impacto desses programas. Em seguida, analisamos os efeitos cognitivos, atitudinais e comportamentais do Parlamento Jovem mineiro. $\mathrm{Na}$ última seção, propomos o modelo unificado, articulando os diferentes fatores que promovem a mudança ou operam como entraves a esta e os diferentes padrões de efeito que se formam como consequência.

\section{Determinantes do impacto dos programas de educação cívica}

São inúmeros os estudos que mostram que atividades de educação cívica têm, em maior ou menor medida, impacto sobre o conhecimento, as atitudes e a participação política. Ao analisar os condicionantes do sucesso desses programas sobre o perfil político dos indivíduos, vários fatores têm sido considerados pela literatura. Um deles é o desenho do programa, incluindo o grau de exposição dos indivíduos (NIEMI; JUNN, 1998; FINKEL; ERNST, 2005), a qualidade do instrutor e, no caso de jovens, a série do aluno (NIEMI; CHAPMAN, 1998). Outro aspecto do desenho do programa considerado está associado ao seu objetivo, que pode variar de simples inclusão de conteúdos políticos no currículo escolar a programas mais abrangentes direcionados para a formação de uma nova cultura política. Além disso, o formato do programa importa, sendo mais eficaz quando a experiência é mais dinâmica e envolve debate (GALSTON, 2001; Finkel, 2003; FinkEL; ERNST, 2005) ou mesmo a participação e a deliberação.

Além do desenho, alguns estudos têm chamado a atenção para a especificidade de cada dimensão do comportamento político afetada pelo programa. A diferença mais óbvia é entre a rigidez das atitudes e a flexibilidade da dimensão cognitiva (NIEMI; JUNN, 1998). Ganhos de informação proporcionados por processos socializadores são muito mais comuns e mais substantivos do que mudanças nas atitudes políticas. A adesão a um regime político, a tolerância em relação a minorias e a posição a respeito de assuntos moralmente carregados tendem a permanecer no estado de inércia. Quando mudam, é o resultado de um processo complexo e de longo prazo.

Entre os estudos sobre educação cívica, dois se destacam por elaborar modelos que tratam de forma sistemática as condições favoráveis para que os programas sejam bem-sucedidos. Niemi e Junn (1998), ao analisar os fatores que explicariam a eficácia do ensino sobre política nas aulas de 
educação cívica, consideram duas dimensões. A primeira é constituída pelos fatores associados à exposição dos conteúdos do conhecimento. O curso (conteúdos, técnicas de ensino, duração etc.), o acesso a livros e jornais e a conversa sobre política em casa são componentes dessa dimensão. Além dos ambientes socializadores, há também uma dimensão constituída por traços do indivíduo que expressam interesse por política e pelo estudo em geral. A motivação é a condição para que o jovem receba as mensagens às quais está exposto.

O segundo estudo, realizado por Finkel e Ernst (2005), demonstra que a qualidade do programa de educação cívica importa. Instrutores interessados e competentes e métodos participativos geram maiores ganhos. De acordo com os autores, a qualidade do programa é mais relevante em relação a aspectos mais resistentes à mudança, como os valores. Se comparadas com as demais dimensões, as mudanças no conhecimento sobre política ocorrem com mais facilidade, não necessitando mais do que o ensino em sala de aula. Já a mudança nos valores exige mais do programa, dependendo menos da instrução formal do que de práticas/métodos (mais ou menos participativos e mais ou menos abertos à discussão) e da qualidade do instrutor.

Nossa análise segue o rumo desses dois estudos no sentido de buscar identificar as condições favoráveis para que programas de educação cívica gerem mudanças no comportamento político dos jovens. Embora o nosso interesse de pesquisa seja menos a efetividade desses programas do que a dinâmica da mudança em relação a atitudes, conhecimento e participação política, os fatores que identificamos aqui coincidem, em grande medida, com aqueles encontrados por esses dois estudos.

Sendo assim, a nossa investigação retoma achados anteriores, mas que ainda não tinham sido pensados de forma articulada, com a preocupação de elaborar um modelo unificado capaz de explicar as condições mais ou menos favoráveis para que haja mudanças quanto a atitudes, conhecimento e participação política dos jovens. Além disso, introduzimos no modelo um fator que não foi considerado por estudos anteriores sobre programas de educação: a saliência do objeto no contexto da experiência (SEARS; VALENTINO, 1997). Esse fator qualifica os demais, potencializando ou amortecendo efeitos esperados. Assim, a distinção entre, de um lado, a dimensão cognitiva, que é facilmente moldável, e, de outro, a dimensão atitudinal, resistente à mudança, deve ser relativizada em função do universo familiar da experiência vivida durante o programa. No universo que investigamos, por exemplo, o contato constante com o Legislativo estadual certamente explica por que os efeitos do programa são mais expressivos em relação aos objetos associados a essa instituição, seja no plano cognitivo, seja no atitudinal. Nesse caso, a questão não se resume ao esforço adicional (FINKEL; ERNST, 2005; FINKEL, 2003) para que o programa impacte os valores, mas inclui também a centralidade que os objetos têm no programa, o que nem sempre está associado ao conteúdo ensinado.

Além de analisar de forma integrada os diversos fatores que criam condições mais ou menos favoráveis à mudança, propomos aqui explorar a implicação desses diferentes fatores na configuração de padrões dos efeitos desses programas. Esses padrões variam porque o tempo e a trajetória dos efeitos dos processos socializadores não seguem o mesmo ritmo e dinâmica para os diversos aspectos do comportamento político. Os diferentes padrões de efeitos dos programas de educação cívica têm despertado menos atenção dos pesquisadores do que os fatores que 
FUKS, M. Explicando os efeitos de programas de socialização política...

potencializam o seu impacto. Ainda assim, alguns estudos têm indicado, além dos efeitos diretos, a presença de efeitos indiretos ou tardios (ANDOLINA et al., 2003; LUSKIN et al., 2007; VERBA; SCHLOZMAN; BRADY, 1995; ZUKIN et al., 2006; LUSKIN; FISHKIN, 2007).

Ao analisar um programa de educação cívica no Brasil - o Parlamento Jovem mineiro pretendemos contribuir para uma compreensão integrada do processo de mudança propiciado por experiências dessa natureza. A abordagem sistemática adotada propõe-se a captar diferentes padrões de mudança, considerando a qualidade e o desenho do programa, a dimensão afetada, a saliência do objeto no contexto da experiência e a motivação individual.

\section{Os efeitos do Parlamento Jovem mineiro}

O Parlamento Jovem (PJ) é um projeto da Escola do Legislativo da Assembleia Legislativa de Minas Gerais (ALMG), desenvolvido conjuntamente com o curso de ciências sociais da PUC Minas desde 2004 e destinado aos alunos do ensino médio de Belo Horizonte ${ }^{1}$. Durante um semestre letivo, alunos dessas escolas desenvolvem uma série de atividades (palestras, oficinas, mesas-redondas, atividades legislativas etc.) e, no final, reúnem-se no plenário da Assembleia Legislativa para a apreciação e a votação de um documento com proposições que, posteriormente, são encaminhadas como projetos de lei para a tramitação na ALMG.

Em sua edição de 2008, o programa teve início em abril e terminou em junho e teve, em média, dez encontros. Na maior parte do tempo, o PJ ocorreu dentro das escolas, com oficinas semanais. Além disso, várias atividades ocorreram na própria ALMG, tais como mesas-redondas, visitas institucionais e oficinas de redação de projetos de lei.

Em cada edição do PJ, os alunos escolhem um tema para debater e, no final do programa, deliberar. O tema da edição de 2008 foi "Jovem e Violência: provocador ou vítima?". As primeiras oficinas abordaram temas de educação cívica, com ênfase nas noções sobre cidadania, democracia e participação política. A maior parte das oficinas foi dedicada ao processo deliberativo. Durante esse período, os jovens estudaram o tema escolhido, assistiram a debates com especialistas na área, elaboraram proposta de legislação e, por fim, deliberaram. Na última etapa do programa, os participantes dividiram-se em grupos de trabalho e, em seguida, realizaram a plenária final. Nesse momento, reunidos no plenário da Assembleia, os jovens votaram o documento com propostas de políticas públicas associadas ao tema "juventude e violência". Nessa última etapa, as propostas vitoriosas foram encaminhadas para tramitação na ALMG.

Em resumo, a edição de 2008 do PJ foi curta e concentrou-se no estudo e no debate sobre um tema específico. Quanto à sua dinâmica, o programa teve um forte componente participativo, direcionado, desde o início, para a atividade legislativa. Sendo promovido e, em parte, sediado pela ALMG, o jovem ficou exposto ao fluxo informacional, aos atores e às atividades que se desenvolvem nesse ambiente.

O desenho de nosso estudo segue a lógica da pesquisa quase experimental (CAMPBELL; STANLEY, 1979), adequada para medir o impacto de experiências socializadoras sobre o

\footnotetext{
${ }^{1}$ A partir de 2010 o projeto, na ALMG, foi estadualizado e o programa específico com as escolas de Belo Horizonte passou a ser realizado pela Câmara de Vereadores de Belo Horizonte, mantendo a participação da PUC Minas.
} 
comportamento político. A partir de uma amostra não aleatória², foram realizadas, em 2008 , duas rodadas de um survey ${ }^{3}$, com 670 entrevistas $^{4}$, sendo 335 antes e 335 após o programa, das quais 167 com participantes e 168 com não participantes. A edição 2008 do PJ contou com sete escolas participantes ${ }^{5}$ e teve como tema "o jovem e a violência". Na seleção do grupo de controle, buscamos assegurar a simetria entre os tipos de escola e entre diferentes fatores do background familiar. Desse modo, foram selecionadas sete escolas com o mesmo perfil socioeconômico e cultural que as escolas dos alunos participantes (pública, privada e militar). Da mesma forma, foram selecionados alunos com perfil semelhante ao dos participantes em relação a uma série de características observáveis, tais como sexo, idade, série, classe social e escolaridade dos pais.

Além da variável de tratamento, incluímos em nossos modelos de regressão algumas variáveis com o objetivo de controlar os efeitos que determinadas estruturas (ambiente familiar e ambiente escolar) exercem sobre o conhecimento, as atitudes e a participação política do jovem. 0 ambiente familiar é, aqui, indicado pela escolaridade dos pais, que é também uma ótima proxy para a participação política dos pais. Já o ambiente escolar é definido pelo tipo de escola que o jovem frequenta (pública, militar, particular de classe média e particular de elite). Outros trabalhos (Fuks; BATISTA, 2011; FUKS, 2011; 2012) demonstraram o impacto substantivo desses contextos sobre o perfil político do jovem, o que reforça a tese, já consolidada na literatura, de que os ambientes familiar e escolar definem, em grande parte, o estoque de conhecimento, os valores e a participação política dos jovens (SLOMCZYNSKI; SHABAD, 1988; ICHILOV, 2007; FINKEL; ERNST, 2005; ANDOLINA et al., 2003; Verba, Burns; ScholozmAn, 2003; VerBa, SCHLOZMAn; BuRNS, 2005).

Para evitar a atribuição de efeitos ao PJ, quando, na realidade, eles estão associados a outras experiências socializadoras que ocorreram durante o mesmo período, incluímos nos modelos a série em que o aluno estudava, a participação em outros programas de educação cívica (ou em grupos de estudos) e a exposição aos meios de comunicação. Os modelos também contêm a variável defasada (o valor da variável dependente na primeira rodada do survey), controlando assim os efeitos derivados das diferentes condições iniciais dos jovens.

Começamos a análise pelo conhecimento sobre política. Seria um exagero afirmar que o Parlamento Jovem teve um impacto inequívoco e uniforme sobre as diversas áreas do conhecimento político. Em relação a várias baterias de perguntas, o grupo de tratamento, quando comparado com o grupo de controle, não obteve ganhos informacionais. O programa não estimulou o aumento do conhecimento sobre o nome e as ideologias dos partidos políticos, nem dos cargos e partidos de lideranças políticas. Surpreendentemente, o PJ também não contribuiu para que os jovens se tornassem mais informados sobre as atribuições do Poder Legislativo no Brasil, como aprovar o orçamento do Executivo e propor e votar leis, ou a respeito do trâmite para a aprovação de uma lei,

\footnotetext{
2 Portanto, os resultados aqui apresentados, embora sejam bastante sugestivos e tenham como referência um amplo número e, especialmente, grande variedade de tipos de escola, não têm validade estatística para o conjunto de alunos de ensino médio de Belo Horizonte.

${ }^{3}$ A primeira rodada foi realizada entre fevereiro e abril e a segunda, entre junho e novembro de 2008.

40 projeto original previa 351 entrevistas no pré-teste e 351 no pós-teste, totalizando 702 entrevistas. Entretanto, apenas 335 foram possíveis no pós-teste. Decidimos excluir da análise os casos faltantes no pós-teste.

5 Participaram dessa edição as seguintes escolas: Colégio Frei Orlando - Unidade Carlos Prates; Colégio Frei Orlando Unidade Alípio de Melo; Colégio Loyola; Escola Santo Tomás de Aquino; Escola Municipal Walt Disney; Colégio Tiradentes Unidade Gameleira; Colégio Tiradentes - Unidade Santa Teresa.
} 
FUKS, M. Explicando os efeitos de programas de socialização política...

como a votação no plenário e a apreciação pela Comissão de Constituição e Justiça do corpo legislativo ${ }^{6}$.

Por outro lado, após participarem do programa, os jovens conseguiram citar um número maior de deputados estaduais e reconhecer um número maior de atividades promovidas pela ALMG junto à sociedade civil. Não menos importante, o grupo de tratamento aprendeu a distinguir as instituições legislativas de demais instituições políticas, assim como o significado de um dos principais procedimentos envolvidos no processo decisório legislativo, o "destaque". Além disso, conforme esperado, quem participou do programa mostrou ter mais conhecimento sobre um dos principais assuntos debatidos: o Estatuto da Criança e do Adolescente. Os jovens também adquiriram conhecimento a respeito do nome das siglas de algumas instituições políticas.

Tabela 1

Conhecimento político

\begin{tabular}{|c|c|c|c|c|c|c|}
\hline & $\begin{array}{l}\text { Eventos } \\
\text { da ALMG }\end{array}$ & $\begin{array}{l}\text { Nome dos } \\
\text { deputados }\end{array}$ & $\begin{array}{l}\text { Instituições } \\
\text { legislativas }\end{array}$ & Siglas & Destaque & $\begin{array}{c}\text { Estatuto da } \\
\text { Criança }\end{array}$ \\
\hline Tratamento & $\begin{array}{l}0,495^{* * *} \\
(0,161)\end{array}$ & $\begin{array}{l}0,679 * * * \\
(0,201)\end{array}$ & $\begin{array}{l}0,334^{*} \\
(0,174)\end{array}$ & $\begin{array}{l}0,167^{*} \\
(0,085)\end{array}$ & $\begin{array}{l}18,009 * * * \\
(7,939)\end{array}$ & $\begin{array}{c}2,301 * * * \\
(0,485)\end{array}$ \\
\hline Escolaridade dos pais & $\begin{array}{c}0,022 \\
(0,107)\end{array}$ & $\begin{array}{c}0,111 \\
(0,114)\end{array}$ & $\begin{array}{c}0,167 \\
(0,125)\end{array}$ & $\begin{array}{c}0,059 \\
(0,075)\end{array}$ & $\begin{array}{l}2,413^{* * * *} \\
(0,772)\end{array}$ & $\begin{array}{l}3,240 * * * \\
(1,317)\end{array}$ \\
\hline $\begin{array}{c}2^{\circ} \text { ano do ensino } \\
\text { médio }\end{array}$ & $\begin{array}{l}-0,046 \\
(0,127)\end{array}$ & $\begin{array}{l}-0,981 \\
(0,163)\end{array}$ & $\begin{array}{l}-0,107 \\
(0,154)\end{array}$ & $\begin{array}{c}0,085 \\
(0,075)\end{array}$ & $\begin{array}{c}1,468 \\
(0,747)\end{array}$ & $\begin{array}{c}0,828 \\
(0,198)\end{array}$ \\
\hline $\begin{array}{c}3^{\circ} \text { ano do ensino } \\
\text { médio }\end{array}$ & $\begin{array}{c}0,260 \\
(0,218)\end{array}$ & $\begin{array}{l}0,851 * * \\
(0,375)\end{array}$ & $\begin{array}{c}0,079 \\
(0,225)\end{array}$ & $\begin{array}{c}0,183 \\
(0,114)\end{array}$ & $\begin{array}{l}7,100 * * * \\
(0,495)\end{array}$ & $\begin{array}{c}1,269 \\
(0,411)\end{array}$ \\
\hline Escola militar & $\begin{array}{c}0,321 \\
(0,344)\end{array}$ & $\begin{array}{c}0,377 \\
(0,368)\end{array}$ & $\begin{array}{l}-0,251 \\
(0,203) \\
\end{array}$ & $\begin{array}{c}0,123 \\
(0,172) \\
\end{array}$ & $\begin{array}{c}20,435^{* * * *} \\
(16,441)\end{array}$ & $\begin{array}{l}0,404^{*} \\
(0,198)\end{array}$ \\
\hline $\begin{array}{c}\text { Escola de classe } \\
\text { média }\end{array}$ & $\begin{array}{l}-0,117 \\
(0,301) \\
\end{array}$ & $\begin{array}{c}0,264 \\
(0,515)\end{array}$ & $\begin{array}{l}-0,154 \\
(0,268) \\
\end{array}$ & $\begin{array}{l}0,180 * * \\
(0,235) \\
\end{array}$ & $\begin{array}{c}11,136^{* * * *} \\
(7,623)\end{array}$ & $\begin{array}{c}0,367 \\
(0,231) \\
\end{array}$ \\
\hline Escola de elite & $\begin{array}{l}-0,078 \\
(0,356)\end{array}$ & $\begin{array}{l}-0,054 \\
(0,428)\end{array}$ & $\begin{array}{l}-0,102 \\
(0,256)\end{array}$ & $\begin{array}{l}0,321 * * \\
(0,240)\end{array}$ & $\begin{array}{l}4,599 * \\
(4,338)\end{array}$ & $\begin{array}{l}0,177 * * \\
(0,134)\end{array}$ \\
\hline Grupo de estudo & $\begin{array}{l}0,297^{*} \\
(0,155) \\
\end{array}$ & $\begin{array}{l}0,341^{*} \\
(0,321) \\
\end{array}$ & $\begin{array}{l}0,733^{* * * *} \\
(0,157)\end{array}$ & $\begin{array}{c}0,221^{* * *} \\
(0,125)\end{array}$ & $\begin{array}{l}2,026 * * \\
(0,736) \\
\end{array}$ & $\begin{array}{l}5,838 * * * \\
(2,853)\end{array}$ \\
\hline Exposição aos meios & $\begin{array}{l}0,044^{* * *} \\
(0,019) \\
\end{array}$ & $\begin{array}{l}0,051^{*} \\
(0,029) \\
\end{array}$ & $\begin{array}{l}0,055^{*} \\
(0,027) \\
\end{array}$ & $\begin{array}{l}0,011^{* * *} \\
(0,019) \\
\end{array}$ & $\begin{array}{l}0,896 * * \\
(0,049) \\
\end{array}$ & $\begin{array}{l}1,197 * * * \\
(0,060)\end{array}$ \\
\hline Variável defasada & $\begin{array}{c}-1,098 * * * \\
(0,152)\end{array}$ & $\begin{array}{c}-0,543^{* * *} \\
(0,149)\end{array}$ & $\begin{array}{c}-0,627^{* * *} \\
(0,056)\end{array}$ & $\begin{array}{c}0,273^{* * *} \\
(0,053)\end{array}$ & - & - \\
\hline Constante & $\begin{array}{c}0,212 \\
(0,321)\end{array}$ & $\begin{array}{l}-0,448 \\
(0,511)\end{array}$ & $\begin{array}{c}2,229 * * * \\
(0,242)\end{array}$ & $\begin{array}{l}0,392^{*} \\
(0,211)\end{array}$ & $\begin{array}{l}0,005^{* * * *} \\
(0,003)\end{array}$ & $\begin{array}{l}0,104 * * * \\
(0,054)\end{array}$ \\
\hline $\mathrm{N}$ & 274 & 294 & 294 & 294 & 294 & 294 \\
\hline Pseudo $R^{2} / R^{2}$ ajustado & 0,286 & 0,230 & 0,316 & 0,182 & $932,49 * * *$ & $131,25^{* * *}$ \\
\hline
\end{tabular}

Fonte: Pesquisa "O Parlamento Jovem como espaço de socialização política".

Os valores nas células das quatro primeiras colunas são coeficientes de regressão linear, com erro-padrão robusto e com cluster no nível da escola apresentado entre parênteses. Os valores nas células da quinta e da sexta coluna são coeficientes de regressão logística (razão de chance), com erro-padrão robusto e cluster no nível da escola apresentado entre parênteses. A tabela mostra apenas as variáveis que apresentaram significância estatística para o grupo de tratamento ou em outra variável relevante para explicar os efeitos do programa, tais como a exposição aos meios de comunicação e a participação em grupo de estudo. Em todos os modelos foi incluída, como controle, a variável defasada, com o valor do survey da primeira rodada.

* Estatisticamente significativo a 0,10

** Estatisticamente significativo a 0,05

*** Estatisticamente significativo a 0,01

${ }^{6}$ Por economia de espaço e para facilitar a leitura, só apresentamos, no artigo, os modelos das variáveis de conhecimento que foram afetadas pelo PJ. 
Em síntese, apesar de os dados não apontarem para uma única direção, podemos identificar um padrão na influência do PJ sobre o conhecimento político dos jovens: o ganho de conhecimento concentra-se nos objetos próximos da experiência socializadora, seja porque eles se referem ao próprio ambiente do PJ, seja porque fazem parte dos conteúdos ensinados. Nesse sentido, é bem provável que as informações a respeito dos eventos legislativos e do nome dos deputados tenham chegado aos jovens mediante a sua imersão no ambiente institucional em que ocorreu o PJ.

Não por acaso, as variáveis mais relevantes nos modelos são a exposição aos meios de comunicação e a participação em grupo de estudo. Em ambos os casos, trata-se de processos de formação cívica que ocorrem simultaneamente e concorrem com o PJ enquanto agente de circulação da informação política. Além de propiciar ganhos de conhecimento em todas as dimensões afetadas pelo PJ, a participação em grupos de estudo ainda gerou um ganho de conhecimento adicional, aumentando a capacidade de o jovem citar o nome dos partidos e identificar suas ideologias políticas.

O padrão de efeitos informacionais do PJ indica que apenas em relação a objetos mais salientes o programa apresenta efeitos mais expressivos do que a participação em grupos de estudos. Isso mostra que o impacto de experiências socializadoras depende da natureza da atividade. Nesse caso, o grupo de estudos, sendo uma atividade exclusivamente voltada para a aquisição de conhecimento político, proporcionou maiores ganhos informacionais do que o PJ, que teve o ensino como apenas uma das suas atividades.

Já os fatores estruturais, associados aos ambientes familiar e escolar, não são os mais adequados para explicar mudanças em processos socializadores de curta duração. A escolaridade dos pais, com certeza, é um dos principais preditores do grau de conhecimento político dos filhos (FUKS; BATISTA, 2011). Mas, entre o começo e o fim do programa, ela não teve nenhum efeito adicional sobre o estoque de informação política dos jovens. O ambiente escolar revelou-se mais relevante, pois, ainda que de forma limitada, os alunos de escolas particulares e militares tiveram ganhos de conhecimento político, se comparados com os alunos de escolas públicas (categoria de referência).

Apesar de se tratar de um programa de natureza participativa, o PJ não tornou o jovem mais engajado em atividades políticas. Outros programas de educação cívica - como, por exemplo, a MiniONU - mostraram-se mais eficazes no sentido de promover a participação política.

Diferentemente da participação, o aumento de exposição à informação e do interesse por política é evidente. Os jovens saíram do PJ mais interessados por política e muito mais expostos ao noticiário político. 
FUKS, M. Explicando os efeitos de programas de socialização política...

Tabela 2

Participação política

\begin{tabular}{|c|c|c|c|}
\hline & Associativismo & $\begin{array}{l}\text { Trabalho voluntário } \\
\text { na escola }\end{array}$ & Ação política \\
\hline Tratamento & $\begin{array}{c}0,956 \\
(0,287)\end{array}$ & $\begin{array}{c}1.245 \\
(0.405)\end{array}$ & $\begin{array}{l}-0,150 \\
(0,162)\end{array}$ \\
\hline Escolaridade dos pais & $\begin{array}{c}0,805 \\
(0,178)\end{array}$ & $\begin{array}{c}1.581 \\
(0.461)\end{array}$ & $\begin{array}{c}0,201 \\
(0,182)\end{array}$ \\
\hline $2^{\circ}$ ano do ensino médio & $\begin{array}{c}1,20 \\
(0,366)\end{array}$ & $\begin{array}{c}1.157 \\
(0.315)\end{array}$ & $\begin{array}{l}0,445^{*} \\
(0,215)\end{array}$ \\
\hline $3^{\circ}$ ano do ensino médio & $\begin{array}{c}1,877 \\
(0,800)\end{array}$ & $\begin{array}{l}0.220^{* * *} \\
(0.114)\end{array}$ & $\begin{array}{l}1,173^{* * *} \\
(0,222)\end{array}$ \\
\hline Escola militar & $\begin{array}{c}0.946 \\
(0,688)\end{array}$ & $\begin{array}{c}0.300 \\
(0.246)\end{array}$ & $\begin{array}{c}0,255 \\
(0,279) \\
\end{array}$ \\
\hline Escola de classe média & $\begin{array}{c}0,937 \\
(0,583)\end{array}$ & $\begin{array}{c}0.819 \\
(0.717)\end{array}$ & $\begin{array}{l}-0,053 \\
(0,305)\end{array}$ \\
\hline Escola de elite & $\begin{array}{l}0,259^{*} \\
(0,188)\end{array}$ & $\begin{array}{c}0.779 \\
(0.714)\end{array}$ & $\begin{array}{c}0,639 \\
(0,379)\end{array}$ \\
\hline Grupo de estudo & $\begin{array}{c}2,15 \\
(1,031)\end{array}$ & $\begin{array}{c}1.053 \\
(0.435)\end{array}$ & $\begin{array}{c}0,364 \\
(0,294)\end{array}$ \\
\hline $\begin{array}{c}\text { Outros programas de educação } \\
\text { cívica }\end{array}$ & $\begin{array}{l}2,55^{* *} \\
(1,10)\end{array}$ & $\begin{array}{c}1.186 \\
(0.636)\end{array}$ & $\begin{array}{l}-0,093 \\
(0,344)\end{array}$ \\
\hline $\begin{array}{l}\text { Exposição aos meios de } \\
\text { comunicação }\end{array}$ & $\begin{array}{c}1,092 \\
(0,074)\end{array}$ & $\begin{array}{l}1.241^{* * * *} \\
(0.102)\end{array}$ & $\begin{array}{c}0,049 \\
(0,043)\end{array}$ \\
\hline Variável defasada & - & - & $\begin{array}{c}-0,427^{* * *} \\
(0,078)\end{array}$ \\
\hline Constante & $\begin{array}{c}0,161 \\
(0,081)\end{array}$ & $\begin{array}{l}0.0482^{* * * *} \\
(0.0407)\end{array}$ & $\begin{array}{l}1,475^{* * *} \\
(0,297)\end{array}$ \\
\hline $\mathrm{N}$ & 287 & 294 & 289 \\
\hline Pseudo $R^{2} / R^{2}$ ajustado & 0,574 & 0,095 & 0,227 \\
\hline
\end{tabular}

Fonte: Pesquisa "O Parlamento Jovem como espaço de socialização política".

Os valores nas células das duas primeiras colunas são coeficientes de regressão logística (razão de chance), com erro padrão robusto com cluster no nível da escola apresentado entre parênteses. Os valores nas células da terceira coluna são coeficientes de regressão linear, com erro-padrão robusto com cluster no nível da escola apresentado entre parênteses. Na última coluna, incluímos, como controle, a variável defasada, com o valor do survey da primeira rodada.

* Estatisticamente significativo a 0,10

** Estatisticamente significativo a 0,05

*** Estatisticamente significativo a 0,01 
Tabela 3

Variáveis motivacionais

\begin{tabular}{|c|c|c|}
\hline & $\begin{array}{c}\text { Exposição aos meios } \\
\text { de comunicação }\end{array}$ & $\begin{array}{c}\text { Interesse por } \\
\text { política }\end{array}$ \\
\hline Tratamento & $\begin{array}{l}0,763^{* *} \\
(0,285)\end{array}$ & $\begin{array}{l}0,265^{* * *} \\
(0,088)\end{array}$ \\
\hline Escolaridade dos pais & $\begin{array}{c}0,009 \\
(0,178)\end{array}$ & $\begin{array}{l}0,099 * \\
(0,056)\end{array}$ \\
\hline $2^{\circ}$ ano do ensino médio & $\begin{array}{c}0,019 \\
(0,311)\end{array}$ & $\begin{array}{l}-0,090 \\
(0,084) \\
\end{array}$ \\
\hline $3^{\circ}$ ano do ensino médio & $\begin{array}{l}0,606 * * \\
(0,229)\end{array}$ & $\begin{array}{c}0,081 \\
(0,105)\end{array}$ \\
\hline Escola militar & $\begin{array}{l}1,157^{* * *} \\
(0,228)\end{array}$ & $\begin{array}{c}0,015 \\
(0,069)\end{array}$ \\
\hline Escola de classe média & $\begin{array}{l}1,019 * * \\
(0,424)\end{array}$ & $\begin{array}{c}0,115 \\
(0,088)\end{array}$ \\
\hline Escola de elite & $\begin{array}{l}0,995^{*} \\
(0,495)\end{array}$ & $\begin{array}{c}0,045 \\
(0,104)\end{array}$ \\
\hline Grupo de estudo & $\begin{array}{c}0,722 \\
(0,517)\end{array}$ & $\begin{array}{l}0,299 * * * \\
(0,095)\end{array}$ \\
\hline Outros programas de educação cívica & $\begin{array}{c}0,227 \\
(0,423) \\
\end{array}$ & $\begin{array}{c}0,075 \\
(0,117)\end{array}$ \\
\hline Exposição aos meios de comunicação & - & $\begin{array}{l}-0,007 \\
(0011)\end{array}$ \\
\hline Variável defasada & $\begin{array}{c}-0,529 * * * \\
(0,036)\end{array}$ & $\begin{array}{c}-0,747^{* * *} \\
(0,088) \\
\end{array}$ \\
\hline Constante & $\begin{array}{l}1,815^{* * *} \\
(0,452)\end{array}$ & $\begin{array}{l}0,310 * * \\
(0,123)\end{array}$ \\
\hline $\mathrm{N}$ & 294 & 294 \\
\hline Pseudo $R^{2} / R^{2}$ ajustado & 0,317 & 0,242 \\
\hline
\end{tabular}

Fonte: Pesquisa "O Parlamento Jovem como espaço de socialização política".

Os valores nas células são coeficientes de regressão linear, com erro-padrão robusto com cluster no nível da escola apresentado entre parênteses. Em todos os modelos, incluímos, como controle,

a variável defasada, com o valor do survey da primeira rodada.

* Estatisticamente significativo a 0,10

** Estatisticamente significativo a 0,05

*** Estatisticamente significativo a 0,01

Pode-se dizer que o Parlamento Jovem despertou o jovem para o mundo da política. Mas o eventual efeito do programa sobre o engajamento cívico seria indireto e mediado pela motivação política. Seguindo essa linha de raciocínio, o jovem que, nesse momento, passa a se interessar e se informar mais sobre política teria maior propensão a se engajar em atividades cívicas no futuro (ZUKIN et al., 2006; LUSKIN; FISHKIN, 2007; FUKS, 2011). Espera-se que o "engajamento intelectual" (ZALLER, 1992) estimule, com o decorrer do tempo, em especial em momentos da vida em que o recrutamento para a participação política ocorra com mais frequência (VERBA; SCHLOZMAN; BRADY, 1995), o envolvimento em atividades cívicas.

Dois fatores fortalecem, no caso da participação política, a tese dos efeitos tardios. O primeiro é de natureza metodológica: o período entre as duas medições da pesquisa foi curto (aproximadamente, quatro meses), o que tornou difícil observar eventuais efeitos dos ganhos de motivação sobre a participação política. Além disso, um jovem, na faixa etária de 14 a 17 anos, tem 
FUKS, M. Explicando os efeitos de programas de socialização política...

poucos incentivos e mesmo oportunidades de participar de atividades políticas típicas da vida adulta, como, por exemplo, aquelas associadas ao mundo do trabalho, ao associativismo e às eleições.

No caso do conhecimento político também observamos essa trajetória do efeito que parte do PJ e passa pelo aumento de atenção em relação à política. Além de seus efeitos diretos sobre o conhecimento, o programa cria condições favoráveis à aquisição de informação política no futuro. Como mostra a Tabela 1, a exposição à informação política nos meios de comunicação é o principal preditor de ganhos de conhecimento durante o PJ. Sabendo que o programa estimula o hábito de se informar, é natural esperar o aumento de conhecimento político como seu efeito indireto e tardio.

Ainda que a maioria dos estudos conclua que os indivíduos que participam de programas de educação cívica se tornam cidadãos mais interessados, ativos e mais bem informados sobre a política, eles não são igualmente otimistas quanto aos seus efeitos nas atitudes políticas dos participantes. Mas, mesmo em relação às atitudes, é importante estabelecer uma distinção entre os diferentes "objetos da política" (ALMOND; VERBA, 1964). A diferença relevante para o nosso estudo é aquela entre objetos específicos e concretos (por exemplo, as instituições políticas) e princípios abstratos (por exemplo, a tolerância política), sendo aqueles mais maleáveis do que estes.

As evidências de que dispomos não deixam dúvidas quanto à maleabilidade de certas atitudes políticas. O aumento expressivo de atitudes positivas em relação ao Legislativo estadual indica a emergência de uma nova imagem pública da ALMG junto aos participantes do programa. Quando comparados com o grupo de controle, esses jovens percebem a ALMG como uma instituição mais transparente, aberta à participação da sociedade e dinâmica e inovadora (FUKS; CASALECCHI, 2012). Além disso, há um aumento substantivo de confiança na ALMG em decorrência da participação no PJ. 
Tabela 4

Confiança nas instituições

\begin{tabular}{|c|c|c|c|}
\hline & ALMG & $\begin{array}{l}\text { Câmara dos } \\
\text { Vereadores }\end{array}$ & $\begin{array}{c}\text { Congresso } \\
\text { Nacional }\end{array}$ \\
\hline Tratamento & $\begin{array}{l}0,355^{* * *} \\
(0,089)\end{array}$ & $\begin{array}{l}0,202^{* * *} \\
(0,059)\end{array}$ & $\begin{array}{c}0,063 \\
(0,047)\end{array}$ \\
\hline Escolaridade dos pais & $\begin{array}{l}0,157^{* *} \\
(0,067)\end{array}$ & $\begin{array}{l}0,167^{* *} \\
(0,077)\end{array}$ & $\begin{array}{l}0,141^{* *} \\
(0,053)\end{array}$ \\
\hline $2^{\circ}$ ano do ensino médio & $\begin{array}{c}0,017 \\
(0,110)\end{array}$ & $\begin{array}{l}-0,007 \\
(0,103)\end{array}$ & $\begin{array}{l}-0,013 \\
(0,065)\end{array}$ \\
\hline $3^{\circ}$ ano do ensino médio & $\begin{array}{c}0,082 \\
(0,193)\end{array}$ & $\begin{array}{c}0,093 \\
(0,072)\end{array}$ & $\begin{array}{l}-0,018 \\
(0,123)\end{array}$ \\
\hline Escola militar & $\begin{array}{l}-0,244 \\
(0,156)\end{array}$ & $\begin{array}{c}-0,304 * * * \\
(0,101)\end{array}$ & $\begin{array}{l}-0,108 \\
(0,084)\end{array}$ \\
\hline Escola de classe média & $\begin{array}{l}-0,171 \\
(0,117)\end{array}$ & $\begin{array}{l}-0,267 \\
(0,155)\end{array}$ & $\begin{array}{l}-0,168 \\
(0,106)\end{array}$ \\
\hline Escola de elite & $\begin{array}{c}-0,326 * * \\
(0,139)\end{array}$ & $\begin{array}{l}-0,186 \\
(0,165)\end{array}$ & $\begin{array}{l}-0,164 \\
(0,118)\end{array}$ \\
\hline Grupo de estudo & $\begin{array}{l}-0,011 \\
(0,109)\end{array}$ & $\begin{array}{l}-0,098 \\
(0,148)\end{array}$ & $\begin{array}{c}-0,148^{*} \\
(0,079)\end{array}$ \\
\hline $\begin{array}{l}\text { Outros programas de } \\
\text { educação cívica }\end{array}$ & $\begin{array}{c}0,057 \\
(0,142)\end{array}$ & $\begin{array}{l}-0,029 \\
(0,079)\end{array}$ & $\begin{array}{c}0,152 \\
(0,130)\end{array}$ \\
\hline $\begin{array}{l}\text { Exposição aos meios de } \\
\text { comunicação }\end{array}$ & $\begin{array}{c}0,011 \\
(0,015)\end{array}$ & $\begin{array}{l}-0,003 \\
(0,018)\end{array}$ & $\begin{array}{c}0,001 \\
(0,017)\end{array}$ \\
\hline Variável defasada & $\begin{array}{c}-0,883^{* * *} \\
(0,100)\end{array}$ & $\begin{array}{c}-0,933^{* * *} \\
(0,106)\end{array}$ & $\begin{array}{c}-0,979 * * * \\
(0,144)\end{array}$ \\
\hline Constante & $\begin{array}{l}0,352^{* * *} \\
(0,132)\end{array}$ & $\begin{array}{l}0,429 * * * \\
(0,127)\end{array}$ & $\begin{array}{l}0,319 * * * \\
(0,076)\end{array}$ \\
\hline $\mathrm{N}$ & 278 & 277 & 273 \\
\hline $\mathrm{R}^{2}$ ajustado & 0,358 & 0,338 & 0,263 \\
\hline
\end{tabular}

Fonte: Pesquisa "O Parlamento Jovem como espaço de socialização política".

Os valores nas células são coeficientes de regressão linear, com erro-padrão robusto com cluster no nível da escola apresentado entre parênteses. Em todos os modelos, incluímos, como controle,

a variável defasada, com o valor do survey da primeira rodada.

* Estatisticamente significativo a 0,10

* Estatisticamente significativo a 0,05

*** Estatisticamente significativo a 0,01

Mais uma vez, chama atenção a influência do programa sobre mudanças nos objetos que fazem parte do universo familiar, nesse caso a própria instituição que o promove e a Câmara dos Vereadores, outro objeto da política local. Como pode ser observado em relação ao Congresso Nacional, as imagens de instituições políticas menos salientes durante o programa não foram afetadas. Com certeza, a presença constante na ALMG, o contato com os seus funcionários e deputados e o intenso fluxo de informações a respeito da instituição favoreceram a mudança atitudinal $^{7}$

Como esperado, as atitudes "fortes" (KROSNICK; PETTY, 1995; KROSNICK, 1991) são mais resistentes à mudança. Já aprendemos com os estudos sobre socialização política que valores nucleares, como aqueles associados a grupos sociais e a temas controversos, se formam cedo. Mas

\footnotetext{
7 Para uma análise mais detalhada desse tema, ver Fuks e Casalecchi (2011).
} 
FUKS, M. Explicando os efeitos de programas de socialização política...

também aprendemos com pesquisas posteriores (JENNINGS; NIEMI, 1974; JenNINGS; MARKUS, 1984; SEARS; VALENTINO, 1997) que processos de socialização que ocorrem depois da infância afetam nossas atitudes e crenças.

Por isso, não chega a ser uma surpresa o fato de o PJ ter sido mais influente do que se esperava na formação de jovens mais tolerantes em relação a grupos sociais que costumam ser alvo de atitudes negativas, como os comunistas, negros e ateus.

Tabela 5

Tolerância (movimento negro, comunistas e ateus)

\begin{tabular}{|c|c|}
\hline & Tolerância política \\
\hline Tratamento & $\begin{array}{l}0,190 * * * \\
(0,062)\end{array}$ \\
\hline Escolaridade dos pais & $\begin{array}{l}-0,017 \\
(0,077)\end{array}$ \\
\hline $2^{\circ}$ ano do ensino médio & $\begin{array}{c}-0,0572 \\
(0,134)\end{array}$ \\
\hline $3^{\circ}$ ano do ensino médio & $\begin{array}{c}0,077 \\
(0,148)\end{array}$ \\
\hline Escola militar & $\begin{array}{l}-0,069 \\
(0,133) \\
\end{array}$ \\
\hline Escola de classe média & $\begin{array}{l}0,710 * * * \\
(0,132)\end{array}$ \\
\hline Escola de elite & $\begin{array}{l}0,627^{* * *} \\
(0,196)\end{array}$ \\
\hline Grupo de estudo & $\begin{array}{c}0,203 \\
(0,224)\end{array}$ \\
\hline $\begin{array}{l}\text { Outros programas de } \\
\text { educação cívica }\end{array}$ & $\begin{array}{c}0,036 \\
(0,140)\end{array}$ \\
\hline $\begin{array}{c}\text { Exposição aos meios de } \\
\text { comunicação }\end{array}$ & $\begin{array}{l}-0,015 \\
(0,016)\end{array}$ \\
\hline Variável defasada & $\begin{array}{c}-0.674 * * * \\
(0,067)\end{array}$ \\
\hline Constante & $\begin{array}{c}5,253 \\
(0,537)\end{array}$ \\
\hline $\mathrm{N}$ & 286 \\
\hline $\mathrm{R}^{2}$ & 0,4062 \\
\hline
\end{tabular}

Fonte: Pesquisa "O Parlamento Jovem como espaço de socialização política".

Os valores nas células são coeficientes de regressão

linear, com erro-padrão robusto com cluster no nível da escola apresentado entre parênteses. Incluímos, como controle, a variável defasada, com o valor do survey da primeira rodada.

* Estatisticamente significativo a 0,10

** Estatisticamente significativo a 0,05

*** Estatisticamente significativo a 0,01

Mas não basta seguir as conclusões mais recentes dos estudos sobre socialização política para entender essas mudanças. Ao menos dois outros fatores devem ser considerados. $O$ primeiro é a influência do clima de debate e participação do PJ. No estudo sobre programas de educação cívica na África do Sul, Finkel e Ernst (2005) já haviam mostrado que o que, de fato, importa para a aquisição 
de "orientações democráticas" é a qualidade do instrutor e o método de ensino. Os efeitos sobre valores democráticos só foram substantivos em contextos em que o programa contou com dinâmicas ativas e participativas ou em que o instrutor tinha certas qualidades. Podemos, então, esperar que a natureza participativa do PJ seja, em parte, responsável pelo ganho de valores democráticos.

O segundo fator é a própria temática do PJ, na edição de 2008: "Jovem e violência: provocador ou vítima?". Durante os meses em que durou o programa, esse tema foi o foco central dos debates, estudos e deliberação, o que obrigou os participantes a refletir sobre a condição dos jovens de camadas socioeconômicas menos favorecidas que praticam crimes ou que, desde muito cedo, ingressam no mercado de trabalho e também sobre o papel do Estado na proteção e punição desses grupos. É provável que a imersão nesse universo temático tenha contribuído para aumentar a tolerância dos jovens em relação a minorias.

Mas nem tudo mudou no campo dos valores e atitudes. A resistência à mudança que caracteriza essa dimensão do comportamento político pode ser observada em relação aos homossexuais. Utilizando a análise fatorial, Fuks (2012) mostrou que as atitudes dos jovens em relação a homossexuais não se alinham nem com suas atitudes em relação a outras minorias, nem com suas posições em relação a temas controversos que, habitualmente, opõem atitudes liberais e conservadoras. Esse limite da ação do PJ merece ser aprofundado em estudos sobre outros programas de educação cívica, avaliando se há, de fato, uma excepcionalidade nas atitudes em relação a homossexuais ou se isso se deve a alguma característica do programa.

\section{Distribuição do impacto do PJ em função da qualidade do programa na escola e da motivação individual}

Seria esse conjunto de efeitos distribuído de forma homogênea entre os participantes do PJ ou haveria alguma variação em função da qualidade do programa em cada escola e da motivação individual? Para responder a essa pergunta, segmentamos a variável de tratamento em função da qualidade do programa ${ }^{8}$ em cada escola e em função do aumento do interesse (declarado pelo jovem) no PJ durante a sua realização. Os dados mostram que tanto a estrutura quanto a motivação interferem nos efeitos do programa, sendo estes mais substantivos nas escolas em que o programa teve melhor desempenho e nos jovens mais motivados.

\footnotetext{
${ }^{8}$ A qualidade do programa foi avaliada por nossa equipe de pesquisa a partir do acompanhamento do programa. Foram considerados os seguintes fatores: qualidade dos monitores, envolvimento do coordenador do programa na escola, infraestrutura e compromisso da direção da escola com as atividades do programa. O coeficiente de Spearman (0.9198) da correlação entre a qualidade do programa nas escolas e a avaliação dos próprios alunos sobre o programa confirma a validade do nosso indicador.
} 
FUKS, M. Explicando os efeitos de programas de socialização política...

Tabela 6

Efeitos da qualidade do programa e da motivação dos participantes

\begin{tabular}{|c|c|c|c|c|c|}
\hline & & \multicolumn{2}{|c|}{ Qualidade do programa } & \multicolumn{2}{|c|}{ Motivação individual } \\
\hline & & $\begin{array}{c}\text { Baixa } \\
\text { qualidade }\end{array}$ & Alta qualidade & $\begin{array}{c}\text { Baixa } \\
\text { motivação }\end{array}$ & Alta motivação \\
\hline \multirow{4}{*}{  } & Siglas & $\mathrm{n} / \mathrm{s}$ & $\begin{array}{l}0,271^{*} \\
(0,136)\end{array}$ & $n / s$ & $\begin{array}{l}0,223^{*} \\
(0,110)\end{array}$ \\
\hline & Nome dos deputados & $\begin{array}{l}0,440 * * \\
(0,202)\end{array}$ & $\begin{array}{l}1,111 * * * \\
(0,255)\end{array}$ & $\begin{array}{l}0,688 * * \\
(0,275)\end{array}$ & $\begin{array}{l}0,674 * * * \\
(0,198)\end{array}$ \\
\hline & Eventos da ALMG & $\begin{array}{l}0,329 * * \\
(0,146)\end{array}$ & $\begin{array}{c}0,848^{* * *} \\
(0,233)\end{array}$ & $\mathrm{n} / \mathrm{s}$ & $\begin{array}{l}0,669 * * * \\
(0,185)\end{array}$ \\
\hline & Destaque & $\begin{array}{c}15,437 * * * \\
(8,393)\end{array}$ & $\begin{array}{c}23,153^{* * * *} \\
(8,690)\end{array}$ & $\begin{array}{c}10,354 * * * \\
(6,506)\end{array}$ & $\begin{array}{c}23,547^{* * * *} \\
(9,838)\end{array}$ \\
\hline \multirow{4}{*}{$\begin{array}{l}\frac{\mathscr{d}}{0} \\
\frac{0}{3} \\
\text { 索 }\end{array}$} & Confiança na ALMG & $\begin{array}{l}0,217^{* *} \\
(0,079)\end{array}$ & $\begin{array}{l}0,593 * * * \\
(0,084)\end{array}$ & $\begin{array}{l}0,271 * * \\
(0,117)\end{array}$ & $\begin{array}{l}0,389 * * * \\
(0,092)\end{array}$ \\
\hline & Confiança no Congresso & $n / s$ & $\begin{array}{l}0,139^{*} \\
(0,066) \\
\end{array}$ & $n / s$ & $n / s$ \\
\hline & $\begin{array}{c}\text { Confiança na Câmara } \\
\text { Vereadores }\end{array}$ & $\begin{array}{l}0,139 * \\
(0,069)\end{array}$ & $\begin{array}{l}0,331^{* *} \\
(0,110)\end{array}$ & $\mathrm{n} / \mathrm{s}$ & $n / s$ \\
\hline & Tolerância aos comunistas & $\begin{array}{l}0,090^{*} \\
(0,044)\end{array}$ & $\begin{array}{l}0,104^{*} \\
(0,058)\end{array}$ & $n / s$ & $\begin{array}{l}0,128^{* * * *} \\
(0,039)\end{array}$ \\
\hline \multirow{2}{*}{ 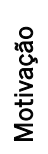 } & $\begin{array}{c}\text { Exposição aos meios de } \\
\text { comunicação }\end{array}$ & $\mathrm{n} / \mathrm{s}$ & $\begin{array}{l}1,339 * * * \\
(0,163)\end{array}$ & $\mathrm{n} / \mathrm{s}$ & $\begin{array}{l}0,908^{* * * *} \\
(0,261)\end{array}$ \\
\hline & Interesse por política & $\begin{array}{l}0,191 * * * \\
(0,047)\end{array}$ & $\begin{array}{l}0,399 * * * \\
(0,044)\end{array}$ & $\mathrm{n} / \mathrm{s}$ & $\begin{array}{l}0,367 * * * \\
(0,076)\end{array}$ \\
\hline
\end{tabular}

Fonte: Pesquisa "O Parlamento Jovem como espaço de socialização política".

Os valores nas células são coeficientes de regressão linear, com erro-padrão robusto com cluster no nível da escola apresentado entre parênteses. Em todos os modelos, incluímos, como controle, a variável defasada, com o valor do survey da primeira rodada. As células não preenchidas são aquelas em que os coeficientes não são estatisticamente significativos. Para a variável "destaque", foi realizada uma regressão logística. Nesse caso, o valor apresentado na célula é a razão de chance. $\mathrm{Na}$ primeira coluna, encontram-se as variáveis de interesse. Nas demais colunas, colocamos as variáveis explicativas, que indicam a qualidade do programa e a motivação do participante. A "alta qualidade" indica o conjunto das escolas em que o programa obteve bom desempenho, enquanto a "baixa qualidade" indica o conjunto das escolas em que o programa não foi bem-sucedido. Nas duas últimas colunas, estão as variáveis indicadoras da motivação dos participantes. Em todos os casos, a categoria de referência é o grupo de controle da pesquisa. Os modelos utilizados para a construção da tabela contaram com as mesmas variáveis que usamos nos demais modelos do artigo. Essas variáveis de controle foram omitidas na tabela por questão de espaço e para facilitar a leitura dos resultados. As variáveis que não foram afetadas pela qualidade do programa ou pela motivação não foram incluídas.

* Estatisticamente significativo a 0,10

** Estatisticamente significativo a 0,05

*** Estatisticamente significativo a 0,01

A força dos efeitos do PJ depende, em grande medida, da sua qualidade e do aumento do interesse do participante. Entre as questões de conhecimento, a estrutura do PJ e a motivação individual só não trazem ganhos adicionais em relação ao Estatuto da Criança e do Adolescente e à identificação das instituições legislativas. A única outra variável que não é afetada pela qualidade e pela motivação é a tolerância em relação a negros e ateus. Por outro lado, são inúmeras as mudanças mediadas, exclusivamente, pelo desempenho do programa e estímulo do jovem. Só há aumento de conhecimento em relação aos objetos que não são salientes nas escolas em que o PJ é bem-sucedido ou quando o jovem se sente motivado para participar do programa. O mesmo acontece com a totalidade das variáveis motivacionais que foram afetadas pelo programa e com a confiança no Congresso Nacional. 
Os coeficientes da Tabela 6 mostram que, se comparado com o grupo de controle, os jovens em cujas escolas o programa foi bem-sucedido tiveram mudanças mais substantivas do que aqueles que declararam que o seu interesse no PJ aumentou durante o programa. Da mesma forma, a qualidade do programa tem efeito sobre um número maior de variáveis (dez) do que a motivação individual (oito). Mas, quando comparamos estratos do próprio grupo de tratamento, os efeitos da motivação superam os da estrutura do programa. Basta observar que, enquanto a qualidade do PJ é, exclusivamente, responsável pelo seu efeito em três das variáveis, o efeito do programa sobre cinco variáveis depende da motivação do participante.

Em conjunto, esses dados nos dizem que não é apenas o desenho do programa, a saliência dos objetos ou a natureza da dimensão do comportamento político que explicam os efeitos do programa. Confirmando e ampliando resultados de pesquisas anteriores (FINKEL; ERNST, 2005; NIEMI; JUNN, 1998), aspectos estruturais e individuais da experiência socializadora, expressos nas condições em que ela se desenvolveu em cada escola e na motivação de quem participou dela, influenciam e, com frequência, condicionam as mudanças cognitivas, atitudinais e comportamentais.

\section{Condições favoráveis à mudança: uma abordagem integrada}

A partir da análise apresentada nas seções anteriores, não é difícil apontar os fatores responsáveis por criar condições mais ou menos favoráveis à ação do PJ na formação de jovens bem informados e interessados por política, participativos, tolerantes e confiantes nas instituições políticas. Os principais são as características de cada dimensão do comportamento político, o grau de saliência dos objetos das atitudes e do conhecimento, o desenho e a qualidade do programa e o interesse de quem participa dele.

A diferença das dimensões aqui analisadas é o que explica o expressivo aumento de interesse e de exposição à informação política. A aquisição de conhecimento político durante o PJ também foi favorecida pela facilidade na transmissão de informação por meio de processos de socialização política. Nosso estudo também demonstrou que, embora sejam mais resistentes à mudança, as atitudes políticas não são homogêneas entre si, pois as atitudes que têm como objeto as instituições mudam com maior facilidade do que as atitudes que constituem o núcleo duro da política simbólica (SEARS; FUNK, 1999), tais como aquelas dirigidas a minorias e assuntos moralmente carregados ${ }^{9}$. Além disso, mesmo atitudes enraizadas, como aquelas associadas à tolerância, sofreram mudanças durante o programa. Associamos essas mudanças à dinâmica ativa e participativa do PJ e ao seu foco temático.

Consideramos também o desenho do programa de educação cívica e os seus conteúdos. O Parlamento Jovem mineiro é um projeto de natureza participativa. Além de estimular o debate, ele "transforma" os jovens em deputados, indo além do convencional "role playing". Os participantes do programa deliberam efetivamente sobre a política pública eleita como tema no encontro inaugural do projeto. Por outro lado, o PJ é um projeto de curta duração, tendo, em média, na edição de 2008 , nove oficinas. Além disso, nesse breve percurso, apenas os primeiros encontros foram dedicados à formação cívica tradicional, mediante a exposição de conteúdos sobre democracia, cidadania e Poder

\footnotetext{
${ }^{9}$ Mas vimos também que, se o programa aborda questões associadas a esses temas e valores, essa resistência pode ser amortecida, como ocorreu na tolerância em relação a algumas minorias.
} 
FUKS, M. Explicando os efeitos de programas de socialização política...

Legislativo. Além dos conteúdos curriculares, cada programa de educação cívica cria o seu próprio universo familiar, ao tornar certos conteúdos mais salientes ou aproximar os participantes de determinadas realidades. No caso do PJ, o universo familiar é composto pelo próprio ambiente em que ele ocorreu, incluindo o Legislativo estadual, os deputados e a dinâmica política regional.

Essas considerações a respeito do desenho do programa e dos objetos salientes nos permitem aprofundar o entendimento de alguns resultados apresentados. Mostramos que o PJ não teve impacto homogêneo nas diversas modalidades de conhecimento analisadas. Quando ocorreu, esse impacto concentrou-se nos objetos salientes durante o programa, tais como as informações a respeito dos eventos legislativos, nome dos deputados e identificação das instituições legislativas. Vimos também os limitados e indiretos efeitos do programa sobre a participação e sugerimos que a curta duração do programa contribuiu para que isso ocorresse. Além disso, apontamos o caráter participativo do PJ como elemento facilitador na formação de jovens mais atentos à política. Esse conjunto de aspectos mostra como as características dos programas de educação cívica podem favorecer ou não mudanças no comportamento político e ajudar a prever o tipo de mudança que deve ocorrer.

Tão importante quanto o desenho e o universo familiar do programa é a sua estrutura. Nas escolas em que essa estrutura se beneficiou de um bom monitor, de um coordenador presente nas oficinas e de uma direção atenta às exigências do programa, ele foi bem-sucedido. Isso faz toda a diferença, pois essas condições não apenas favoreceram ou limitaram a mudança. Muito mais do que isso, elas condicionaram os efeitos do programa, de tal forma que, em muitos casos, esses efeitos só ocorreram em escolas em que o PJ foi bem-sucedido. Além disso, nas escolas em que o programa teve maior qualidade, houve ganhos adicionais de conhecimento, tolerância, confiança e interesse político. Ou seja, mesmo nos casos em que não determinou a mudança, a qualidade do programa ampliou a sua magnitude.

Não menos importante para fechar o nosso modelo explicativo dos efeitos do programa sobre o perfil político dos jovens é a motivação individual. Essa motivação opera no modelo da mesma forma que a estrutura do programa: em alguns casos ela é condição e, em outros, ela modula os efeitos do PJ. São raros os casos em que a motivação ou a estrutura não interferem no padrão de efeito do programa.

Reunindo os principais pontos apresentados nesta seção, a Tabela 8 apresenta o modelo explicativo proposto neste artigo. Esse quadro sinóptico contém os diferentes fatores que, de forma integrada, contribuíram para explicar os efeitos do PJ, assim como os padrões de efeito ${ }^{10}$ gerados pelo programa.

\footnotetext{
$10 \mathrm{O}$ desenho de nossa pesquisa não permite observar efeitos indiretos, pois não há antecedência temporal entre as variáveis, ou melhor, todas acompanham, simultaneamente, o mesmo fluxo temporal. Mas ele permite identificar tendências, prevendo efeitos tardios a partir dos efeitos de certas variáveis, no tempo 1, sobre outras variáveis, no tempo 2 da nossa pesquisa, como, por exemplo, o efeito da exposição à informação sobre o conhecimento político, o que indica que o impacto cognitivo do programa pode ser maior do que o observado durante o período da coleta de dados.
} 
Quadro 1

Condicionantes e padrões de efeito do Parlamento Jovem mineiro

\begin{tabular}{|c|c|c|c|c|c|}
\hline & $\begin{array}{c}\text { Resistência à } \\
\text { mudança }\end{array}$ & $\begin{array}{l}\text { Características } \\
\text { relevantes do } \\
\text { programa }\end{array}$ & $\begin{array}{l}\text { Qualidade do } \\
\text { programa }\end{array}$ & $\begin{array}{l}\text { Motivação do } \\
\text { participante }\end{array}$ & Padrão do efeito \\
\hline $\begin{array}{c}\text { Confiança na } \\
\text { ALMG }\end{array}$ & Média & Objeto saliente & $\begin{array}{l}\text { Aumenta o } \\
\text { efeito }\end{array}$ & Aumenta o efeito & Efeito direto \\
\hline $\begin{array}{l}\text { Confiança na } \\
\text { Câmara dos } \\
\text { Vereadores }\end{array}$ & Média & Objeto saliente & $\begin{array}{l}\text { Aumenta o } \\
\text { efeito }\end{array}$ & $\begin{array}{c}\text { Não interfere no } \\
\text { efeito }\end{array}$ & Efeito direto \\
\hline Tolerância & Alta & $\begin{array}{l}\text { Curta duração } \\
\text { Objeto saliente }\end{array}$ & $\begin{array}{l}\text { Aumenta o } \\
\text { efeito }\end{array}$ & $\begin{array}{c}\text { Responsável pelo } \\
\text { efeito }\end{array}$ & $\begin{array}{c}\text { Efeito parcial } \\
\text { (comunistas, } \\
\text { movimento } \\
\text { negro e ateus) }\end{array}$ \\
\hline $\begin{array}{c}\text { Conhecimento } \\
\text { sobre assuntos } \\
\text { salientes } \\
\text { durante o } \\
\text { programa }\end{array}$ & Baixa & Objeto saliente & $\begin{array}{l}\text { Aumenta o } \\
\text { efeito }\end{array}$ & $\begin{array}{c}\text { Aumenta o efeito } \\
\text { (nome dos } \\
\text { deputados) } \\
\text { Responsável } \\
\text { pelo efeito } \\
\text { (eventos da } \\
\text { ALMG) }\end{array}$ & $\begin{array}{l}\text { Efeito direto } \\
\text { Efeito tardio e } \\
\text { indireto via } \\
\text { exposição aos } \\
\text { meios de } \\
\text { comunicação }\end{array}$ \\
\hline $\begin{array}{c}\text { Exposição aos } \\
\text { meios de } \\
\text { comunicação }\end{array}$ & Baixa & $\begin{array}{c}\text { Dinâmica } \\
\text { participativa }\end{array}$ & $\begin{array}{l}\text { Responsável } \\
\text { pelo efeito }\end{array}$ & $\begin{array}{c}\text { Responsável pelo } \\
\text { efeito }\end{array}$ & Efeito direto \\
\hline $\begin{array}{l}\text { Interesse por } \\
\text { política }\end{array}$ & Baixa & $\begin{array}{c}\text { Dinâmica } \\
\text { participativa }\end{array}$ & $\begin{array}{l}\text { Aumenta o } \\
\text { efeito }\end{array}$ & $\begin{array}{c}\text { Responsável pelo } \\
\text { efeito }\end{array}$ & Efeito direto \\
\hline Participação & Média & $\begin{array}{l}\text { Curta duração } \\
\text { Dinâmica } \\
\text { participativa }\end{array}$ & $\begin{array}{c}\text { Não interfere } \\
\text { no efeito }\end{array}$ & $\begin{array}{c}\text { Não interfere no } \\
\text { efeito }\end{array}$ & $\begin{array}{c}\text { Efeito tardio e } \\
\text { indireto via } \\
\text { motivação }\end{array}$ \\
\hline
\end{tabular}

Fonte: Pesquisa "O Parlamento Jovem como espaço de socialização política".

\section{Considerações Finais}

A análise empreendida neste artigo constatou que os efeitos do Parlamento Jovem não são distribuídos de forma homogênea em suas diferentes áreas de impacto (informacional, atitudinal e comportamental), nos distintos objetos do conhecimento e das atitudes políticas (mais ou menos salientes) e nas diferentes dimensões do engajamento político (comportamental ou motivacional). Disso, derivamos algumas conclusões: 1 ) as atitudes políticas associadas a valores são mais resistentes à mudança do que a motivação e o conhecimento político e mesmo do que atitudes diante das instituições políticas; 2) os ganhos cognitivos e mudanças atitudinais ocorrem com maior intensidade quando o objeto pertence ao universo familiar da experiência; 3) os efeitos sobre a participação política não se manifestam no presente, mas os fatores de natureza motivacional são indicadores de uma propensão do jovem à participação na vida adulta.

Mas nossa intenção era ir além da avaliação dos impactos do Parlamento Jovem mineiro e explorar a dinâmica e os mecanismos que definem diferentes padrões de influência de programas de educação cívica. Com esse propósito, esboçamos um modelo explicativo desses diferentes padrões, levando em conta os fatores que contribuíram para criar condições mais ou menos favoráveis para a eficácia do programa. $\mathrm{O}$ grau de resistência à mudança de cada dimensão investigada, o desenho e o conteúdo do programa e a saliência do objeto são partes integrantes do modelo. Mas é a qualidade 
FUKS, M. Explicando os efeitos de programas de socialização política...

do programa e a motivação do participante que se destacam, pois, em muitos casos, condicionam a influência dos demais fatores.

Observando o que há de singular na experiência do Parlamento Jovem mineiro, destaca-se a emergência de uma cultura política local. Isso se expressou tanto na nova imagem pública do Legislativo mineiro como no conhecimento adquirido a respeito de instituições e atores políticos do estado de Minas Gerais.

Por último, não podemos deixar de considerar a natureza incremental do processo de formação do perfil político do jovem. Sendo assim, parte dos efeitos de programas de educação cívica como o PJ depende de sua interação com outras experiências em curso ou que estão por vir. Isso ficou claro quando mostramos que outras experiências de socialização política, como, por exemplo, o grupo de estudo, tiveram impactos tão ou mais expressivos do que o Parlamento Jovem mineiro.

\section{Referências Bibliográficas}

Andolina, M., et al. "Habits from Home: lessons from School: influences on youth civic engagement". Political Science \& Politics, vol. 36, $\mathrm{n}^{\circ} 2$, p. 275.280, 2003.

Almond, G.; VerBA, S. The civic culture: political attitudes and democracy in five nations. Princeton: Princeton University Press, 1989 [1964].

Campbell, A., et al. The American voter. New York: John Wiley and Sons, 1960.

CAMPBELL, D. E. "Voice in the classroom: how an open classroom climate fosters political engagement among adolescents". Political Behavior, vol. 30, p. 437-454, 2008.

Campbell, D.; Stanley, J. Delineamentos experimentais e quase-experimentais de pesquisa. São Paulo: Edusp, 1979.

ECKSteIn, H. A. "Culturalisty theory of political change". American Political Science Review, vol. 82, p. 789-804, 1988.

FINKEL, S. E. "Can democracy be taught?". Journal of Democracy, vol. 14, p. 137-151, 2003.

FINKEL, S. E.; SABATINI, C.; BeVIS, G. "Civic education, civil society, and political mistrust in a developing democracy: the case of the Dominican Republic". World Development, vol. 28, p. 1.851-1.874, 2000.

FINKEL, S. E.; ERNST, H. R. "Civic education in post-apartheid South Africa: alternative paths to the development of political knowledge and democratic values". Political Psychology, vol. 26, n³, p. 333-64, 2005.

FinkEL, S. E.; SMith, A. E. "Civic education, political discussion, and the social transmission of democratic knowledge and values in a new democracy: Kenya 2002". American Journal of Political Science, vol. 55, n², p. 417.435, 2011.

FUKS, M. "Efeitos diretos, indiretos e tardios: trajetórias da transmissão intergeracional da participação política". Lua Nova, vol. 83, p. 145-178, 2011.

"Atitudes, cognição e participação política: padrões de influência dos ambientes de socialização sobre o perfil político dos jovens". Opinião Pública, vol. 18, n 1, p. 88-108, 2012.

Fuks, M.; Batista PereiRA, F. "Informação e conceituação: um estudo sobre a dimensão cognitiva da desigualdade política entre jovens de Belo Horizonte". Revista Brasileira de Ciências Sociais, vol. 26, n 76, p. 123.143, 2011.

Fuks, M.; CASAlECCHI, G. "Trust and political information: attitudinal change among participants in the Youth Parliament in Brazil". Brazilian Political Science Review, vol. 6, n 1, p. 70-88, 2012.

Galston, W. "Political knowledge, political engagement, and civic education". Annual Review Political Science, vol. 4, $\mathrm{n}^{\circ} 1$, p. $217 \cdot 234,2001$.

ICHILOV, O. "Civic knowledge of high school students in Israel: personal and contextual determinants". Paper presented at the annual meeting of the International Society of Political Psychology, Portland, Oregon USA, 2007. 
Jennings, M. K.; Markus, G. B. "Partisan orientations over the long haul: results from the three-wave political socialization panel study". The American Political Science Review, vol. 78, n 4, p. 1.000-1.018, 1984.

Jennings, M. K.; NiemI, Richard G. The political character of adolescence: the influence of families and schools. Princeton: Princeton University Press, 1974.

KROSNICK, J. "The stability of political preferences: comparison of symbolic and nonsymbolic attitudes". American Journal of Political Science, vol. 35, n 3, p. 577-586, 1991.

Krosnick, J.; Pettr, R. Attitude strength: an overview. In: Krosnick, J.; Petty, R. (orgs.). Attitude strength: antecedents and consequences. New Jersey: Lawrence Erlbaum Associates, 1995.

Lazarsfeld, P.; Berelson, B.; Gaudet, H. The people's choice: how to voter makes up his mind in a presidential campaign. $2^{\mathrm{a}}$ ed. New York: Columbia University Press, 1965.

LUSKIN, R., et al. "Deliberation in the schools: a way of enhancing civic engagement?". Presented at the biennial General Conference of the European Consortium for Political Research, Pisa, Italy, 2007.

NIEMI, R.; JunN, J. Civic education: what makes students learn. New Haven: Yale University Press, 1998.

Niemi, R.; Chapman, C. "The civic development of 9th- through 12th-grade students in the United States: 1996". Statistical Analysis Report. National Center for Education Statistics, U.S. Department of Education, 1998.

Putnam, R. Comunidade e democracia: a experiência da Itália moderna. Rio de Janeiro: Fundação Getúlio Vargas, 1996.

SEARS, D.; FUnK, C. "Evidence of the long-term persistence of adults' political predispositions". The Journal of Politics, vol. 61, n 1, p. 1.28, 1999.

Sears, D.; Valentino, N. "Politics matters: political events as catalysts for preadult socialization". The American Political Science Review, vol. 91, n 1, p. 45.65, 1997.

SLOMCZYNSKI, K. M.; SHABAD, G. "Can support for democracy and the market be learned in school? A natural experiment in post-communist Poland. Political Psychology, vol. 19, n 4, p. 749.779, 1988.

Valentino, N.; Sears, D. "Event-driven political communication and the preadult socialization of partisanship". Political Behavior, vol. 1, $\mathrm{n}^{\circ}$ 2, p. 127-154, 1998

Verba, S.; Burns, N.; Scholozman, L. "Unequal at the starting line: creating participatory inequalities across generations and among groups". The American Sociologist, vol. 34, p. 45·69, 2003.

Verba, S.; Schlozman, L.; Brady, E. Voice and equality. civic voluntarism in American politics. Cambridge, Mass, London: Harvard University Press, 1995.

Verba, S.; Schlozman, L.; BuRns, N. Family ties: understanding the intergenerational transmission of participation. In: ZUCKerman, A. (org). The social logic of politics. Philadelphia: Temple University Press, 2005.

ZALLER, J. The nature and origins of mass opinion. Cambridge: Cambridge University Press, 1992.

ZUkIN, C., et al. A new engagement? Political, civic life, and the changing American citizen. Oxford: Oxford University Press, 2006. 
FUKS, M. Explicando os efeitos de programas de socialização política...

\section{Anexo \\ Construção das variáveis}

\section{Independentes}

Série

Foi criada uma variável categórica em que $1=$ aluno de $1^{\circ}$ ano, $2=$ aluno de $2^{\circ}$ ano e $3=$ aluno de $3^{\circ}$ ano. Em seguida, essa variável decomposta tem três variáveis binárias que indicam se o aluno participava do primeiro, segundo ou terceiro ano, sendo que o valor $0=$ não participa e $1=$ participa.

Outros programas de educação cívica

Foi perguntado se "Você participa ou já participou de MiniONU", "Você participa ou já participou de Conferência Diplomática" e "Você participa ou já participou de algum outro projeto voltado para a formação política". A partir das respostas criamos uma nova variável, a qual indica se o jovem participou de MiniONU, Conferência Diplomática ou outro projeto de formação política. Atribuímos os seguintes valores: $0=$ não participou de nenhum desses programas e $1=$ participou de algum desses programas.

Grupo de estudo

Foi perguntado se "Você participa ou já participou de grupo de estudo sobre política". Atribuímos os seguintes valores: $0=$ não participou e $1=$ participou.

Escolaridade dos pais

Foi criado um construto a partir da Análise Fatorial por Eixos Principais que aglutinou os anos de escolaridade completos do pai e da mãe do respondente, de modo a obter apenas uma variável geral de escolaridade dos pais. As duas variáveis isoladas foram medidas em termos dos graus escolares completos ou incompletos do pai e da mãe. Para transformá-las em variáveis contínuas, atribuímos os seguintes valores para os anos de escolaridade: 0 (nunca frequentou a escola), 2 (da $1^{\text {a }}$ à $4^{\mathrm{a}}$ série do fundamental incompleto), 4 (da $1^{\mathrm{a}}$ à $4^{\mathrm{a}}$ série do fundamental completo), 6 (da $5^{\mathrm{a}}$ à $8^{\mathrm{a}}$ série do fundamental incompleto), 8 (da $5^{\mathrm{a}}$ à $8^{\mathrm{a}}$ série do fundamental completo), 9,5 (do $1^{\circ}$ ao $3^{\circ}$ ano do ensino médio incompleto), 11 (do $1^{\circ}$ ao $3^{\circ}$ ano do ensino médio completo), 13 (curso superior incompleto), 15 (curso superior completo), 16 (pós-graduação incompleta) e 17 (pós. graduação completa). Participação política dos pais: foi também criado um construto por Análise Fatorial por Eixos Principais que aglutinou a participação política do pai e da mãe do respondente. Os índices de participação política do pai e da mãe foram construídos a partir da contagem do número de associações, partidos e sindicatos dos quais os pais dos respondentes participam.

Variáveis binárias das escolas

Uma das variáveis, em nosso banco de dados, buscava captar em um só indicador o tipo de ambiente escolar frequentado pelo respondente. As categorias definidas foram as seguintes: escola pública, escola pública militar, escola particular de classe média e escola particular de elite. Foram criadas variáveis indicadoras (binárias) a partir das quatro categorias. Os critérios utilizados na classificação das escolas como de elite e classe média foram a mensalidade e a localização 
geográfica. Assim, nenhuma escola de classe média tem, no $1^{\circ}$ e $2^{\circ}$ ano do ensino médio, mensalidade superior a $\mathrm{R} \$ 520,00$, enquanto as mensalidades das escolas de elite variam entre $\mathrm{R} \$$ 642,00 e $R \$$ 738,00. Da mesma forma, além de serem reconhecidas publicamente como "tradicionais", todas as escolas de elite se situam na região mais valorizada de Belo Horizonte (zona sul). Já as escolas de classe média ficam em regiões menos "nobres" da cidade. No caso das escolas públicas e militares, a classificação apenas reproduz a identidade jurídica dessas escolas.

Eficácia política subjetiva

Fizemos a seguinte pergunta: "Às vezes política e governo parecem tão complicados que uma pessoa como você não pode realmente entender o que se passa". A resposta era dada numa escala de Likert, de cinco pontos, com as seguintes alternativas: concordo totalmente, concordo em parte, nem concordo nem discordo, discordo em parte e discordo totalmente. Criamos uma variável binária, excluindo a opção do meio e agregando os dois pares das pontas, de tal forma que cada uma das novas categorias expressasse a totalidade das atitudes em uma das duas direções (concordando ou discordando).

Exposição à informação nos meios de comunicação

Foi perguntado com que frequência o respondente se considerava exposto à informação política em certos meios de comunicação, mais especificamente três tipos: a) TV e rádio; b) jornais e revistas impressos; e c) internet. Para cada um dos três tipos foi fornecida uma escala com a gradação de exposição do respondente $(0$ = nunca, 1 = raramente, 2 = algumas vezes por mês, $3=$ algumas vezes por semana, 4 = diariamente). 0 índice de exposição aos meios de comunicação foi feito a partir do somatório das respostas às três questões, de modo a constituir uma variável contínua.

\section{Dependentes}

Exceto o "associativismo" e a "participação em trabalho voluntário na escola", as variáveis dependentes foram construídas pelo resultado da subtração do seu valor da segunda rodada pelo seu valor da primeira rodada, o que permite estimar o efeito do tratamento.

\section{Conhecimento político}

Conhecimento das siglas

Foi pedido que os respondentes dissessem o significado das siglas TRE (Tribunal Regional Eleitoral), ONU (Organização das Nações Unidas), UNE (União Nacional dos Estudantes) e MST (Movimento dos Sem Terra). As respostas eram abertas e foram pós-codificadas em três níveis (2 = acerto substantivo, 1 = acerto quanto ao tema, 0 = erro ou não resposta). 0 índice foi construído através da Análise Fatorial Exploratória por Eixos Principais, com Alpha de Cronbach de 0,597. Todas as variáveis tiveram cargas satisfatórias, apesar de não tão altas. Oito dos 351 casos não possuíam resposta e foram imputados no valor 0 (na escala de -2 a +2 ). 
FUKS, M. Explicando os efeitos de programas de socialização política...

Destaque

Um dos procedimentos que fazem parte da tomada de decisão no Legislativo é o "destaque". Uma proposta é destacada: 1) quando se deseja manifestar o apoio total ao seu conteúdo; 2) quando o tema discutido foi abordado superficialmente; 3) com vistas à promoção de alguma modificação ou supressão; ou 4) para votação em bloco; 5) ou você não saberia dizer; 7. NR 9. NS. Criamos, então, uma variável binária, atribuindo o valor "1" à resposta correta (3) e o valor "0" às demais respostas.

Estatuto da Criança e do Adolescente

$\mathrm{Na}$ segunda rodada do survey, fizemos a seguinte pergunta: "O Estatuto da Criança e do Adolescente é uma legislação que foi aprovada pelo: 1. Congresso Nacional; 2. Assembleia Legislativa de Minas Gerais; 3. Supremo Tribunal de Justiça; 4. Conselho Nacional dos Direitos da Criança e do Adolescente; 5. Ou você não saberia dizer". Criamos, então, uma variável binária, sendo a resposta correta (Congresso Nacional) $=1 ;$ e as demais alternativas $=0$.

Citação de deputados

Foi feita a pergunta "Você saberia me dizer o nome de algum deputado da Assembleia Legislativa de Minas Gerais?". A pergunta foi repetida até esgotar o número de deputados que o entrevistado sabia citar. Foram atribuídos dois pontos para a citação de nome completo de um deputado e um ponto para o nome incompleto. Em seguida foram somados os pontos, criando-se, assim, um índice.

Conhecimento dos eventos da ALMG

Foi feita a seguinte pergunta ao entrevistado: "A Assembleia Legislativa de Minas Gerais oferece várias possibilidades de participação à população mineira. Você saberia citar alguma destas possibilidades?". Caso não houvesse resposta espontânea, era perguntado ao candidato se ele conhecia: a) seminário legislativo, b) fóruns técnicos, c) audiências públicas, d) comissão de participação popular. A variável foi então construída a partir das respostas de tipo espontânea e forçada. Para cada resposta espontânea foram atribuídos dois pontos. Para cada resposta forçada foi atribuído um ponto. Elas foram então somadas compondo uma escala.

\section{Motivacionais}

Interesse por política

Foi perguntado ao entrevistado o quanto ele se interessava por política. A pergunta continha quatro opções de resposta: nada interessado (0), pouco interessado (1), interessado (2) e muito interessado (3).

\section{Participação política}

Participação em trabalho voluntário na escola

Foi feita a pergunta: "Considerando apenas este ano, 2008, você realizou ou está realizando algum trabalho voluntário organizado pela escola?". A partir daí foi criada uma variável binária, sendo não $=0$ e sim $=1$. 
Associativismo

Na segunda rodada do survey, foi feita a pergunta: "Desta lista de associações ou grupos, eu gostaria de saber de qual você é, atualmente, membro, ou associado, ou participa com frequência?". O seguinte elenco de associações foi apresentado ao entrevistado: a) associação comunitária, de moradores ou sociedade de amigos de bairro; b) associação ligada à defesa de direitos de minoria, tais como o movimento negro, indígena, feminista ou de liberdade de opção sexual; c) associação ligada a temas sociais, tais como saúde, educação, moradia, meio ambiente, cultura; d) sindicato; e) Orçamento Participativo. Devido à baixa participação dos jovens em associações da sociedade civil, transformamos os cinco pontos da escala de associativismo em uma variável binária, indicando se o jovem tem, ao menos, um vínculo associativo.

Ações políticas

Utilizamos um conjunto de variáveis que se referem à participação individual em atividades políticas específicas. Foram consideradas as seguintes atividades: participar de reunião do bairro ou da comunidade, assinar manifesto ou abaixo-assinado, participar de manifestações ou passeatas e participar de greves. Atribuindo o mesmo peso a cada uma das quatro atividades, essa variável passou a ter três categorias: 1) não participou de nenhuma ação, 2) participou de uma ação e 3) participou de duas ou mais ações.

\section{Atitudes políticas}

Confiança na Câmara dos Vereadores

Foi feita a pergunta "Em relação à Câmara dos Vereadores, você: 1) nunca confia, 2) confia às vezes, 3) confia na maior parte do tempo e 4) confia sempre?”. A partir daí uma variável binária foi criada, sendo que nunca confia e confia às vezes $=0$ e confia na maior parte do tempo e confia sempre $=1$.

Confiança no Congresso Nacional

Foi feita a pergunta "Em relação ao Congresso Nacional, você: 1) nunca confia, 2) confia às vezes, 3) confia na maior parte do tempo e 4) confia sempre?". A partir daí uma variável binária foi criada, sendo que nunca confia e confia às vezes $=0$ e confia na maior parte do tempo e confia sempre $=1$.

Confiança na ALMG

Foi feita a pergunta "Em relação à Assembleia Legislativa de Minas Gerais (ALMG), você: 1) nunca confia, 2) confia às vezes, 3) confia na maior parte do tempo e 4) confia sempre?". A partir daí uma variável binária foi criada, sendo que nunca confia e confia às vezes $=0$ e confia na maior parte do tempo e confia sempre $=1$.

Tolerância política (comunistas, membros do movimento negro e ateus)

Uma bateria de perguntas buscava captar a tolerância dos respondentes em relação a certos grupos sociais. O fraseado era o seguinte: "Em muitos lugares existem grupos de pessoas com ideias diferentes das da maioria da população. Em sua opinião, os (comunistas, membros do movimento negro e ateus)"; e as categorias de resposta revelavam três níveis de tolerância (0 = "Devem deixar de 
FUKS, M. Explicando os efeitos de programas de socialização política...

lado suas ideias aceitando as da maioria"; 1 = "Podem ter suas ideias, sem ter permissão de falar sobre elas em público"; 2 = "Podem ter suas ideias e também falar sobre elas em público"). As respostas dadas em relação a comunistas, membros do movimento negro e ateus foram aglutinadas pela Análise Fatorial Exploratória por Componentes Principais.

Mario Fuks·mariofuks@uol.com.br

Submetido à publicação em outubro de 2013. Versão final aprovada em abril de 2014. 